\title{
Current State of Three-Dimensional Myocardial Strain Estimation Using Echocardiography
}

\author{
Ruta Jasaityte, MD, Brecht Heyde, MSc, and Jan D'hooge, PhD, Leuven, Belgium; Trondheim, Norway
}

\begin{abstract}
With the developments in ultrasound transducer technology and both hardware and software computing, real-time volumetric imaging has become widely available, accompanied by various methods of assessing three-dimensional (3D) myocardial strain, often referred to as 3D speckle-tracking echocardiographic methods. Indeed, these methods should provide cardiologists with a better view of regional myocardial mechanics, which might be important for diagnosis, prognosis, and therapy. However, currently available 3D speckle-tracking echocardiographic methods are based on different algorithms, which introduce substantial differences between them and make them not interchangeable with each other. Therefore, it is critical that each 3D speckle-tracking echocardiographic method is validated individually before being introduced into clinical practice. In this review, the authors discuss differences and similarities of the currently available 3D strain estimation approaches and provide an overview of the current status of their validation. (J Am Soc Echocardiogr 2012; $\mathbf{\square}: \mathbf{\square}-\mathbf{\square}$.)
\end{abstract}

Keywords: Echocardiography, Myocardial deformation, 3D strain, Validation, Heart

Ultrasonic myocardial deformation imaging offers the possibility of quantifying regional cardiac deformation noninvasively. It is widely used for the detection of myocardial ischemia ${ }^{1-3}$ and has been proposed as a tool to detect heart disease at its preclinical stage, ${ }^{4-6}$ to differentiate among various hypertrophy etiologies, ${ }^{7}$ and to monitor therapy. ${ }^{8,9}$

Traditionally, cardiac motion and deformation analysis was limited to a visual inspection of the image sequence, in which each myocardial segment was assigned a wall motion score. However, this methodology depended considerably on the expertise of the interpreter ${ }^{10}$ and showed relatively low interobserver agreement. ${ }^{11}$

For this purpose, myocardial strain (i.e., the relative lengthening or shortening of the myocardial segment expressed as a percentage of its initial length) and strain rate (i.e., the rate of this lengthening or shortening) imaging was introduced. ${ }^{12,13}$ For further details, the reader is referred to previous literature. ${ }^{14}$ At present, the assessment of one-dimensional strain with Doppler tissue imaging (DTI) is a well-established technique to regionally quantify myocardial function. ${ }^{14-16}$ This technique requires high frame rates, which may be difficult to obtain in dilated ventricles. However, it can be overcome by reducing the imaging sector width. Therefore, this should not be considered a true limitation of the technique. On the other hand, just as with other Doppler techniques, this technique is angle dependent, as only the strain component along

From the Department Cardiovascular Sciences, Laboratory of Cardiovascular Imaging and Dynamics, Catholic University of Leuven, Leuven, Belgium (R.J., B.H., J.D.); and Medical Imaging Lab, Norwegian Institute for Science \& Technology, Trondheim, Norway (J.D.).

Jan D'hooge has research contracts and/or has provided services to the following ultrasound companies: GE Healthcare, Siemens Medical Solutions, Philips Healthcare, VisualSonics. In addition, Jan D'hooge has been serving as a consultant for Epsilon Imaging (Ann Arbor, Michigan).

Reprint requests: Ruta Jasaityte, MD, Catholic University of Leuven, Department of Cardiovascular Sciences, Lab of Cardiovascular Imaging and Dynamics, U. Z Gasthuisberg, Herestraat 49, 3000 Leuven, Belgium (E-mail: ruta.jasaityte@ uzleuven.be).

0894-7317/\$36.00

Copyright 2012 by the American Society of Echocardiography.

http://dx.doi.org/10.1016/j.echo.2012.10.005 the ultrasound beam can be measured. Although it allows the measurement of longitudinal strain (LS) in all left ventricular (LV) segments, radial strain (RS) and circumferential strain (CS) can only be measured in a limited number of LV segments.

Non-Doppler-based, two-dimensional (2D) strain estimation methods can partly overcome these limitations. Various echocardiographic techniques have been proposed, which use raw radiofrequency signals ${ }^{17}$ or apply block-matching techniques, often termed speckle-tracking (ST) techniques, on B-mode images. ${ }^{18}$ Several of these methods based on 2D ST have already been commercialized. ${ }^{18,19}$ However, six acquisitions of different parasternal and apical LV views are still required to obtain all strain components in all LV segments. This can be an issue in certain experimental and clinical situations, particularly when heart rate or LV loading conditions change rapidly.

With developments in ultrasound transducer technology and both hardware and software computing, systems capable of acquiring realtime volumetric LV data are now widely available. Most of the systems use electrocardiographic (ECG) gating to construct three-dimensional (3D) data from smaller subvolumes acquired at subsequent cardiac cycles (i.e., stitching). As such, reasonable spatial and temporal resolution of 3D data sets can be achieved. The ability to estimate true 3D myocardial motion and deformation using various 3D ST echocardiography (STE) approaches may provide cardiologists with a better view of regional myocardial mechanics, which may be important for diagnosis, prognosis, and therapy. These 3D approaches can measure all strain components in all LV segments from a single acquisition. $^{20-22}$ Furthermore, they are angle independent, do not suffer from strain estimation errors associated with out-of-plane motion, and may in theory allow more precise calculations of LV twist and as sessment of shear strain components.

However, tracking in three dimensions naturally poses some challenges. The increased field of view of volumetric images comes at the cost of both spatial and temporal resolution of the data set. In other words, the current volumetric data sets show a coarser speckle pattern and a higher speckle decorrelation between subsequent volumes. The latter effect becomes even more pronounced in data sets acquired at high heart rates (e.g., during stress echocardiography). Moreover, 


\begin{tabular}{|l|}
\hline \multicolumn{1}{|c|}{ Abbreviations } \\
\hline CS $=$ Circumferential strain \\
DTI = Doppler tissue imaging \\
ECG = Electrocardiography \\
LS = Longitudinal strain \\
LV = Left ventricular \\
MRI = Magnetic resonance \\
imaging \\
RS = Radial strain \\
ST = Speckle tracking \\
STE = Speckle-tracking \\
echocardiography \\
3D = Three-dimensional \\
2D = Two-dimensional \\
\hline
\end{tabular}

because of the amount of data available in volumetric data sets, the computational load is also higher compared with $2 \mathrm{D}$ data sets. These aspects pose a challenging environment for myocardial motion and deformation imaging.

Given the potential of 3D STE techniques and a multitude of publications that have recently appeared in medical journals, we felt that a comprehensive overview that would make this area more accessible to the reader was lacking. In this review, we thus discuss differences and similarities among the currently available 3D STE approaches and provide an overview of their first validation and clinical application studies.

\section{THREE-DIMENSIONAL STRAIN ESTIMATION APPROACHES}

\section{General Work Flow}

All currently available techniques follow the same subsequent steps to estimate 3D strain. This is illustrated in Figures 1 to 4.

In the initial step, key cardiac events are indicated: end-systole and end-diastole. This can be done automatically (e.g., on the basis of the electrocardiogram) or manually (e.g., by visually inspecting the cardiac cycle and indicating the frames with the smallest and largest volumes, respectively; Figure 1). Second, the region of interest for strain estimation is defined. Depending on the software, the endocardial border, sometimes in combination with the epicardial border, is delineated manually, semiautomatically, or automatically. Typically, this involves contouring the end-diastolic frame, although some software packages may require repeating the process for the end-systolic frame as well (Figure 2). Next, the left ventricle is subdivided into segments for segmental strain analysis, usually ranging from 16 to 18 segments depending on the segmentation model used. An anatomic landmark (e.g., the right ventricular insertion point) is used to indicate the orientation of the segments (Figure 3). Finally, the 3D LV region of interest is tracked throughout the cardiac cycle, and the deformation curves are estimated (Figure 4 ). The main differences between the currently available 3D STE algorithms are found in this final step. Their underlying principles are briefly discussed in the next sections.

\section{Block Matching}

The most common 3D STE approach is based on block matching, which can be considered a direct extension of 2D ST to three dimensions. $^{22}$ This technique is based on the assumption of a stable local speckle pattern between subsequent volumes. Local tissue motion can then be extracted from the displacement of those speckle patterns from one frame to another (Figure 5). Because the motion estimates are performed independently from one another, they are usually noisy. An a posteriori regularization step (e.g., by spatially smoothing the initial motion estimates) is therefore often performed. ${ }^{23}$ Note that this approach also works on volumetric data acquired through ECG gating, given that no stitching artifacts appear in the volumetric data (otherwise, the assumption of a stable speckle pattern between subsequent frames is violated).

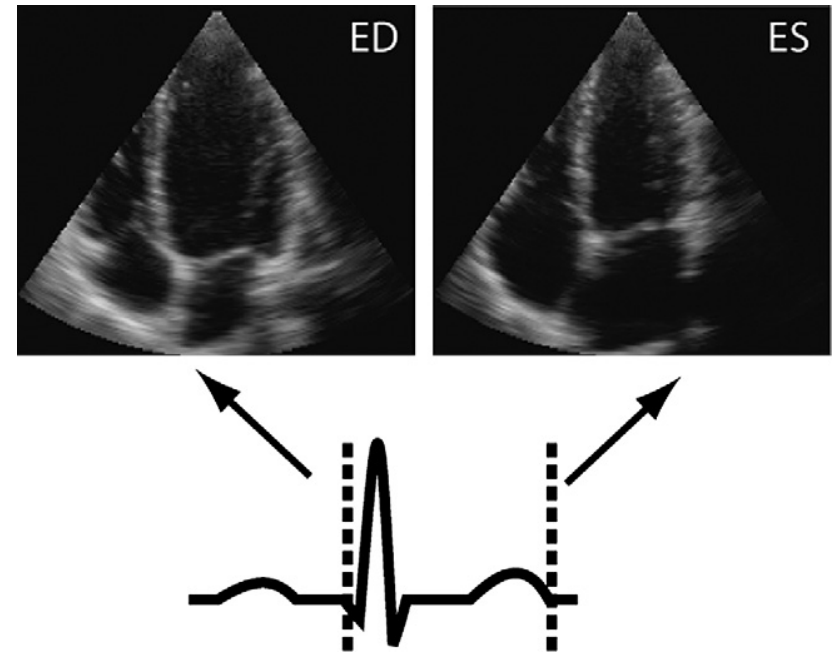

Figure 1 General work flow to estimate 3D strain. Step 1: identification of key cardiac events. Typically, end-diastole (ED) and end-systole $(E S)$ are identified by visual inspection of the cardiac cycle or by using the ECG signal.

It is a popular approach because of its conceptual simplicity and high computational speed. Several commercial implementations of this method are available. ${ }^{24-30}$

\section{Elastic Registration}

Elastic or nonrigid image registration methods use image-warping techniques to estimate cardiac motion between subsequent volumes. In this method, one image is deformed in multiple steps to look as similar as possible to the next image in the image sequence. Once both images match optimally, interframe motion is known (Figure 6). As opposed to the block-matching approaches, the motion of the whole myocardium is thus estimated simultaneously. However, not all warping solutions are feasible or desired. Therefore, additional conditions are imposed during the motion estimation process (e.g., by enforcing the tissue motion to be smooth in space and/or time). For more details, the reader is referred to previously published articles discussing the technical aspects of elastic image registration. ${ }^{31,32}$ Currently, this method has been used mostly in academic circles $^{21,32-34}$ and will be made commercially available. ${ }^{35}$

\section{Model-Based Approach}

Models incorporating a priori knowledge can also be used to guide the 3D myocardial motion and strain estimation process. Different sources may be used as input to this model; for example, a biomechanical model can describe the deformation of myocardium, incorporating the presence of myocardial fibers, ${ }^{20}$ or a statistical model can describe the typical shape of the left ventricle, its typical appearance (i.e., the local grayscale properties of the myocardium), or even its typical motion. ${ }^{36}$

Using a statistical model for motion estimation consists of two stages (Figure 7). The first step involves building a large annotated database containing manually segmented volumetric data sets of healthy and pathologic hearts. This database is then used to learn the normal and pathologic geometry and appearance or motion of a ventricle offline. In the second step, myocardial motion in a new data set can be estimated online by combining and comparing the image data with 


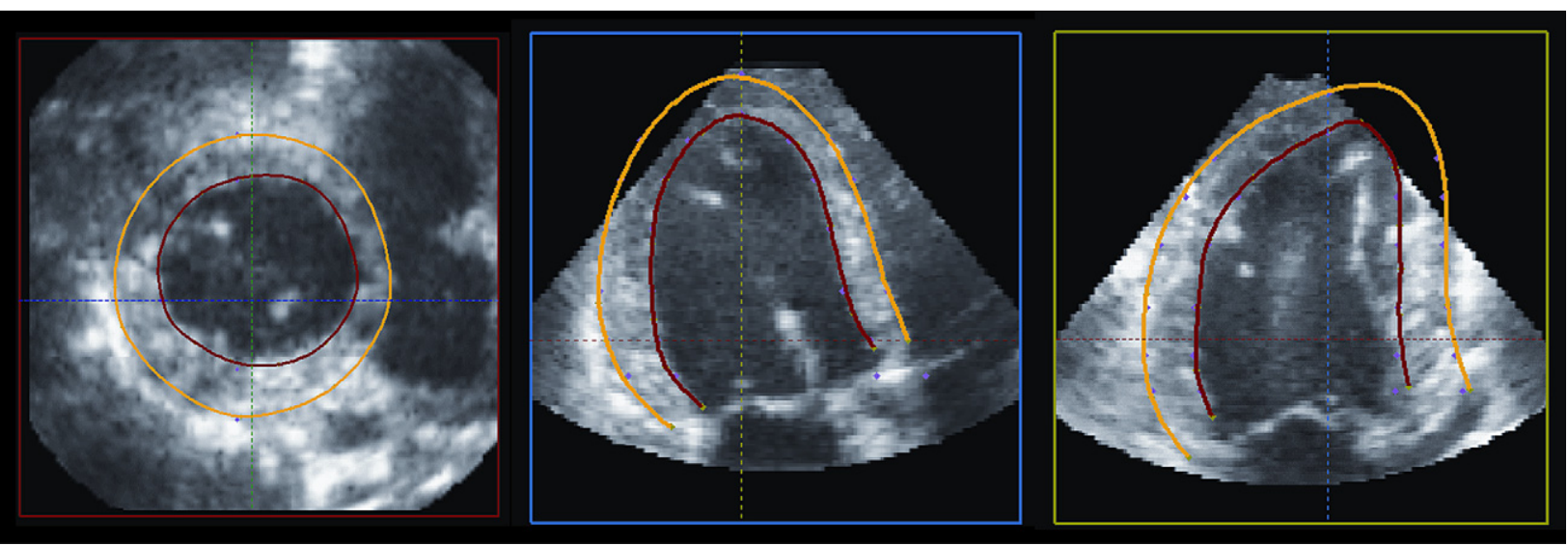

Figure 2 General work flow to estimate 3D strain. Step 2: identifying the myocardium. The region of interest for strain estimation is either manually delineated or identified (semi)automatically by the software. Several views provide the user with visual feedback about the quality of the segmentation.
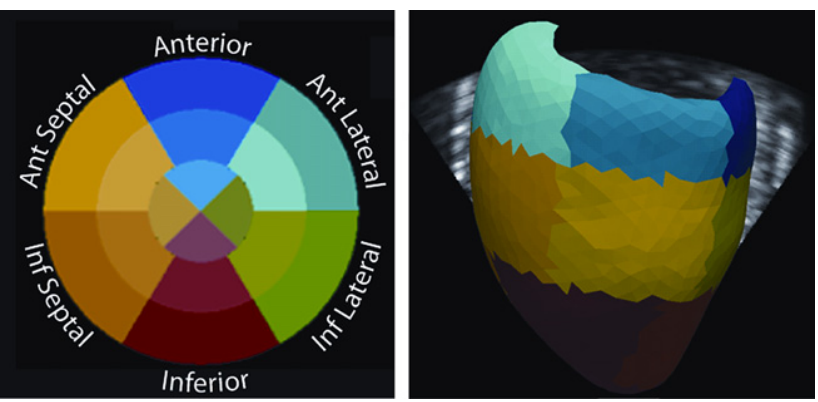

Figure 3 General work flow to estimate 3D strain. Step 3: preparing for regional functional analysis. From the segmentation in step 2, a 3D LV surface can be built, which is subdivided into several segments (ranging from 16 to 18 depending on the segment model). These segments are usually color coded for visual inspection.

the database. The expertise of the clinical experts delineating the ventricles is thus captured and used as a priori knowledge.

To improve tracking performance, block-matching results from a selected number of speckles can be included in the motion estimation process. This method has been implemented in the software of one of the manufacturers. ${ }^{37-40}$

\section{VALIDATION}

Although all 3D STE methods measure the same deformation of the heart, they do so in different ways. Furthermore, within the same category of 3D STE methods, different implementations may exist (e.g., different regularization choices or postprocessing steps). This was demonstrated in a recent study by Gayat et al. ${ }^{41}$ highlighting intervendor dependency of strain measurements, although they were all based on the same underlying 3D STE approach (i.e., block matching). Therefore, it is critical that every method is validated individually before being introduced into clinical practice.

The validation of any strain imaging method and its implementation into clinical routine can be regarded as a four-step process, beginning with a validation on simulated models. In the next step, the method is usually validated using in vitro and in vivo experiments Finally, its implementation in clinical practice can begin. In every step, deformation measurements are compared against a reference measurement (i.e., a ground truth). With every stage, ultrasound images become more realistic (i.e., containing more image artifacts and having an increased level of noise), while obtaining a ground truth deformation measurement becomes more complicated. An overview of the current validation statuses of the available 3D STE approaches is given in Table 1 .

\section{Validation in Simulated Models}

Synthetic ultrasound images can be simulated using dedicated software. The shape and the underlying heart motion are typically simplified (e.g., by representing the left ventricle by the top half of an ellipsoid or by simulating the motion by finite element modeling). Simulated images offer many advantages for testing the performance of a strain estimation method. The displacement (and thus strain) value is known precisely at every image point, and the sensitivity of a method to image acquisition parameters can be investigated in de tail (e.g., the signal-to-noise ratio and frame rate). Dysfunctional regions can also be included to test the method's ability to detect wall motion abnormalities. Although these images have realistic image quality, image artifacts often encountered in clinical images are usually not present, because they are difficult to simulate.

To date, block matching-based ${ }^{22,42,43}$ and elastic registrationbased $^{21,34} 3$ D STE approaches have been shown to perform well in simulated models. These approaches provide reliable deformation curves throughout the cardiac cycle in the longitudinal, circumferential, and radial direction. Some studies have demonstrated that a simulated infarct area could be detected (i.e., an area of low deformation compared with neighboring segments). ${ }^{21,22,42}$ Moreover, the capability of two methods to capture the underlying torsional motion has also been investigated. ${ }^{21,22}$

\section{Validation in an In Vitro Experimental Setting}

In vitro validation involves constructing deformable cardiac phantoms, which are made of a tissue-mimicking material with similar acoustic properties as myocardial tissue. ${ }^{32}$ Myocardial scar can be mimicked by embedding inclusions of a stiffer material into the phantom wall. The phantom is then mounted into a hydraulic pumping system and submerged in a water tank to allow scanning. ${ }^{44}$ As an alternative to tissue-mimicking phantoms, some groups have attached 

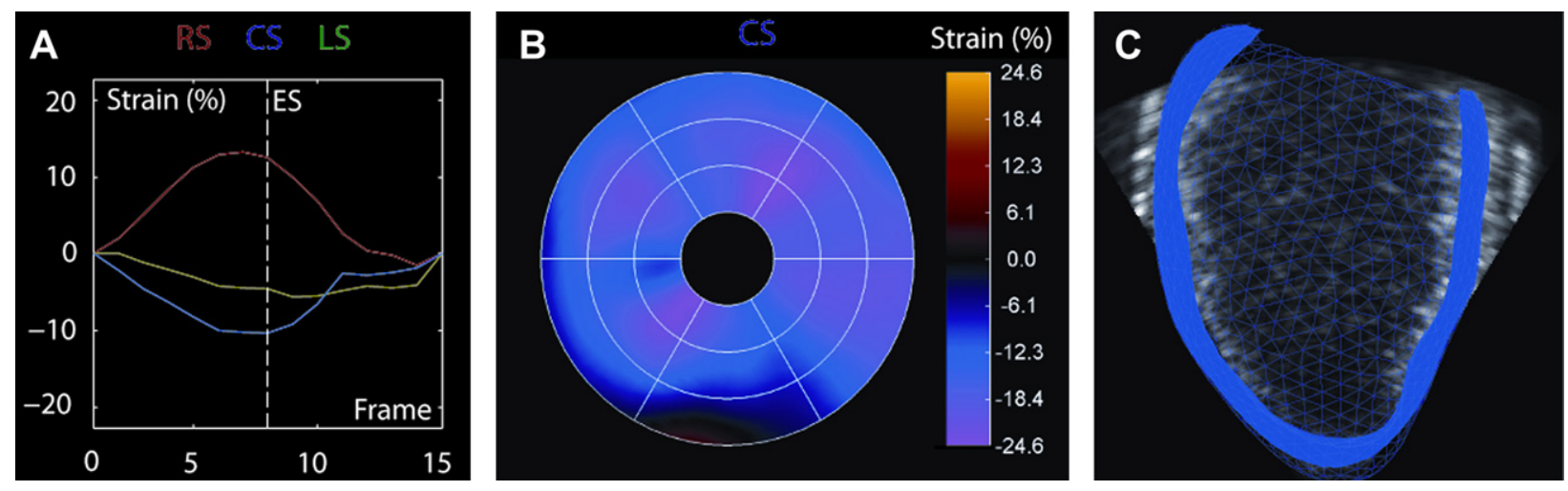

Figure 4 General work flow to estimate 3D strain. Step 4: myocardial tracking. After tracking the LV surface, deformation is estimated and presented in different ways, for example, (A) with strain curves for different segments, (B) using bull's-eye plots, or (C) by showing the deformed surface. ES, End-systole; RS, radial strain; CS, circumferential strain; LS, longitudinal strain.
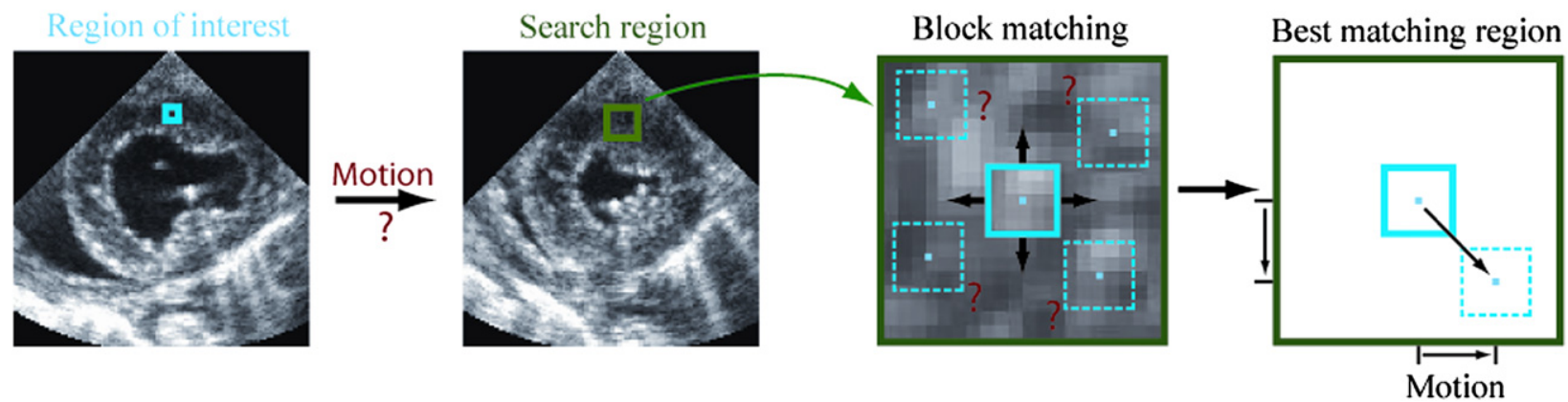

Figure 5 Principle of block matching. A speckle pattern within a region of interest is identified in one frame and tracked within a search region of the successive frame. After comparing this block with all possible matching regions within this search region (dotted blocks), the position of the best matching block compared with the original block determines tissue motion. By repeating this process for multiple region-of-interest blocks, motion between two successive frames for the whole myocardium may be estimated.

excised animal hearts to the setup. ${ }^{25,45}$ These hearts are deformed using a water-filled balloon secured within the LV cavity. At this stage, reference segmental strain values are obtained from the displacements of attached sonomicrometry crystals. In contrast to the simulated models, ground-truth displacement and deformation are known only in the regions where crystals are implanted.

Preliminary results of several studies on the in vitro validation of $3 \mathrm{D}$ block-matching methods ${ }^{25,45-47}$ and 3D speckle-tracking echocardiography on the basis of elastic registration ${ }^{32}$ are readily available. These studies report good correlations between 3D STE and sonomicrometric regional LS ( $r=0.85-0.99)$, CS ( $r=0.80-0.99), 25,32,45,47$ and RS $(r=0.98){ }^{32}$ The results of these studies are summarized in Table 2 .

The capability of a 3D STE method based on elastic registration to detect dysfunctional regions was tested in vitro by Heyde et al. ${ }^{32}$ In that study, only LS and CS, but not RS, could discriminate regions of simulated myocardial scar.

\section{Validation in an In Vivo Experimental Setting}

The third validation step is performed in vivo using open-chest animal models. At this stage, LV deformation is controlled indirectly by pharmacologic inotropic stimulation, and regional myocardial ischemia is induced by coronary artery ligation. Just as in an in vitro setting, sonomicrometric strain curves can be used as reference measurements
Some groups have also described magnetic resonance imaging (MRI) opaque markers that can be implanted in the myocardium to estimate reference strain values. ${ }^{48}$ The results of the 3D STE validation studies performed in this setting are also summarized in Table 2.

More than a decade ago, Papademetris et al. ${ }^{20,49}$ were the first to report on the in vivo validation of a model-based 3D STE approach against sonomicrometry ${ }^{20}$ and opaque MRI markers. ${ }^{49}$

In more recent years, different implementations of block matching-based approaches, ${ }^{50-54}$ a new implementation of a modelbased approach, ${ }^{40}$ and an elastic registration 3D STE approach ${ }^{56}$ have been validated in an in vivo setting. All these studies reported moderate to good correlations $(r=0.49-0.91)$ between regional strain values obtained by 3D STE methods and sonomicrometry ${ }^{40,51,56}$ (Table 2). However, care should be taken in interpreting and comparing those results, as not all of the studies reported strain values corresponding to a local cardiac coordinate system (i.e., RS, LS, and CS). In some of these studies, principal strain components (i.e., strain values along the three major directions in which no shear strain occurs) were measured instead. 20,49,57

In general, the RS component showed the worst correlation and agreement with sonomicrometry for all the tested approaches. To overcome this shortcoming, myocardial incompressibility may be as sumed, and RS can then be computed from the other strain components or expressed in terms of the endocardial surface area change during the cardiac cycle (Figure 8). In the latter case, the resulting 


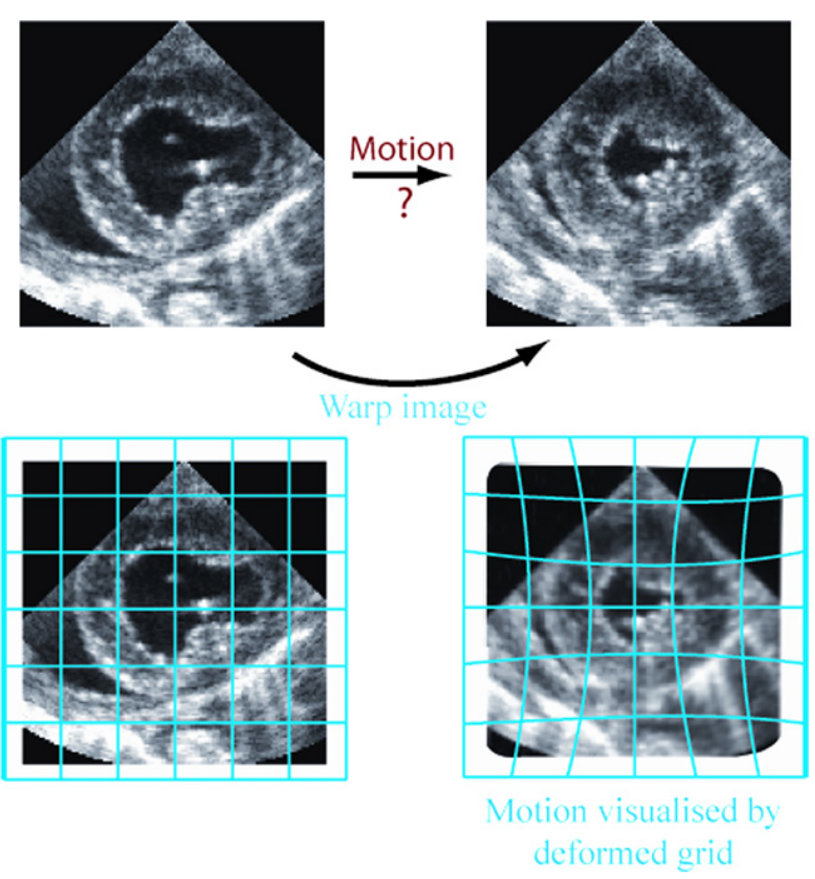

Figure 6 Principle of elastic registration. The whole image is deformed in multiple steps to look as similar as possible to the next image in the ultrasound sequence. This process can be visualized with a grid, which is attached to the underlying image. By manipulating this grid, the underlying image deforms. When both images match, the structure of the grid determines the motion for the whole myocardium at once.

deformation parameter is typically called "area strain" or "area change ratio." For further details, the reader is referred to the Appendix.

Indeed, in an in vivo validation study against sonomicrometry, area change ratio could detect myocardial ischemia as well as standard strain components, and it appeared to be advantageous in discriminating between states of increased and decreased contractility. ${ }^{54}$

Finally, in an in vivo study by Ashraf et al., ${ }^{53}$ one of the 3D blockmatching approaches was shown to be able to detect LV twist.

\section{COMPARISON AGAINST OTHER TECHNIQUES AND CURRENT APPLICATIONS OF 3D SPECKLE-TRACKING ECHOCARDIOGRAPHY IN A CLINICAL SETTING}

Validating methods in a clinical setting is challenging because no reference measures of myocardial deformation are available. The new deformation imaging technique can be compared against only one of the currently available and widely used methods (e.g., DTI, 2D ST, MRI tagging). However, because none of the available noninvasive deformation imaging techniques can be considered a goldstandard method, the results of such comparisons should be interpreted with caution. Rather than indicating if one method performs better than the other, they show only the comparability of strain values among different techniques.

To date, the block matching-based 3D STE software offered by some manufacturers, ${ }^{24,28,29,55,58,59}$ as well as an elastic registration approach, ${ }^{60}$ have been compared with 2D ST. CS and RS estimates obtained by the software of two different vendors ${ }^{50,61}$ have been compared with MRI tagging-derived strain estimates. The results of these studies are summarized in Table 2. It should be noted that most studies report only global strain values, ${ }^{24,28,29,58,61}$ while only one block-matching method ${ }^{55}$ and one elastic registration approach $^{60}$ have so far been compared with 2D ST at a regional level.

\section{Three-Dimensional Speckle-Tracking Echocardiography for the Estimation of Global LV Function}

Several recent publications indicate that 3D speckle-tracking echocardiography is a trustworthy technique for the evaluation of global LV function. ${ }^{24,28,29,58,61,62}$ Reant et al., ${ }^{24}$ Hayat et al., ${ }^{58}$ and Kleijn et al. ${ }^{62}$ all demonstrated good correlations $(r=0.81-0.91)$ between 3D STE global strain and conventional parameters of global LV systolic function such as ejection fraction and Doppler-derived cardiac output. ${ }^{24}$ Moreover, 3D global LS values have been shown to be significantly lower in patients with known ischemic heart disease ${ }^{60}$ and patients with hypertension ${ }^{63}$ compared with controls. Reduced global 3D CS has been reported only in patients with ischemic heart disease. ${ }^{60}$

Besides that, all of the published comparative studies have reported good correlations between global LS values obtained with 3D STE methods and with 2D ST $(r=0.72-0.91 \text {; Table } 2)^{24,58-60}$ The reported limits of agreement (in absolute strain) between these two techniques were $\pm 5 \%$ with respect to the bias. ${ }^{24,58-60}$ It is also worth noting that in general, all of the 3D STE methods tend to measure less deformation compared with 2D ST. The blockmatching approach offered by one manufacturer ${ }^{59}$ and an elastic registration approach ${ }^{60}$ reported approximately 3\% lower absolute strain values compared with 2D ST, whereas for the blockmatching software offered by another manufacturer, this difference was only $0.5 \%$ lower absolute strain values. ${ }^{58}$ Interestingly, global CS extracted by 3D speckle-tracking echocardiography seemed to be $10 \%$ higher (i.e., more negative) in comparison with tagged MRI. ${ }^{61}$

\section{Three-Dimensional Speckle-Tracking Echocardiography for the Estimation of Regional LV Function}

To date, myocardial deformation imaging is most widely applied in the setting of ischemic heart disease, for which detecting areas of regional myocardial dysfunction is as important as estimating global LV function. However, it still remains unclear whether 3D STE regional strain values are as reliable as those obtained by DTI or 2D ST.

In the clinical setting, delayed enhancement MRI is commonly used as a gold-standard method to locate and quantify the extent of myocardial scar. As such, measured segmental strain values can be compared against those segments identified as being scar tissue. It is important to note that this is not a direct comparison of two techniques, as strain is a parameter of myocardial function, whereas delayed enhancement MRI characterizes the ventricle morphologically.

To date, delayed enhancement MRI has been used as a reference method by only one 3D STE study, in which Hayat et al. ${ }^{58}$ found significantly decreased segmental LS, CS, and RS values obtained by both 3D block matching and 2D ST in the segments identified as transmural myocardial scar.

Occasionally, strain values are compared with the wall motion scores estimated by eyeballing. However, the meaningfulness of such comparisons is questionable, as wall motion scoring is known to be rather subjective and to require considerable expertise of the observer. $^{10}$

Despite 3D STE methods being capable of detecting regional LV dysfunction, both regional LS and CS values extracted with a block-matching method ${ }^{55}$ or an elastic registration approach ${ }^{60}$ 


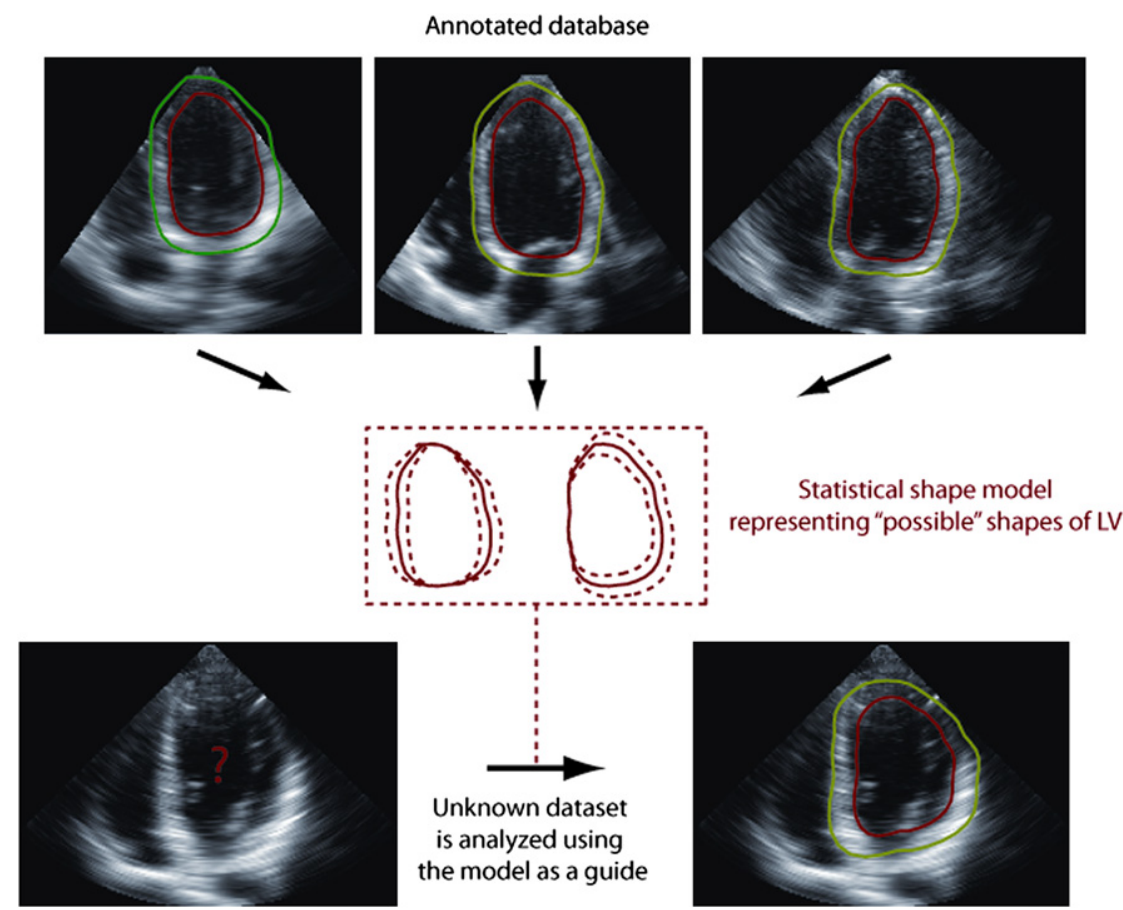

Figure 7 Principle of model-based motion estimation. Myocardial motion is estimated using a priori knowledge. In this case, a large database is segmented first by clinical experts to determine how a typical heart appears and moves in ultrasound images. As such, a statistical model is built. This process is computationally intensive and is therefore performed offline. Myocardial motion of an unknown ultrasound sequence can then be estimated online by comparing it with the preprocessed database.

Table 1 Overview of the current validation status of available 3D STE approaches

\begin{tabular}{|c|c|c|c|c|}
\hline 3D STE approach & Simulated models & In vitro experimental setting & In vivo experimental setting & $\begin{array}{l}\text { Comparison with other methods } \\
\text { in clinical setting }\end{array}$ \\
\hline Block matching & $\begin{array}{l}\text { Jia et al. }(2007)^{46, \dagger} \\
\text { Orderud et al. }(2008)^{42} \\
\text { Crosby et al. }(2009)^{22} \\
\text { Langeland et al. }(2010)^{43, \star}\end{array}$ & $\begin{array}{l}\text { Ashraf et al. }(2010)^{45, *} \\
\text { Jia et al. }(2007)^{46, \dagger} \\
\text { Byram et al. }(2010)^{80} \\
\text { Sahn et al. }(2011)^{25, *} \\
\text { Hjertaas et al. }(2011)^{47, *}\end{array}$ & $\begin{array}{l}\text { Duan et al. }(2007)^{50, \dagger} \\
\text { Seo et al. }(2009)^{51} \\
\text { Jia et al. }(2009)^{52, \dagger} \\
\text { Duan et al. }(2009)^{57} \\
\text { Ashraf et al. (2010) }{ }^{53} \\
\quad \text { (for twist motion) }^{5} \\
\text { Seo et al. }(2011)^{54}\end{array}$ & $\begin{array}{l}\text { Duan et al. }(2007)^{50} \\
\text { Saito et al. }(2009)^{28} \\
\text { Perez de Isla et al. }(2009)^{29} \\
\text { Maffessanti et al. }(2009)^{55} \\
\text { Zhang et al. }(2011)^{26, *} \\
\text { Negishi et al. }(2011)^{59} \\
\text { Reant et al. }(2012)^{24} \\
\text { Hayat et al. }(2012)^{58} \\
\text { Kleijn et al. }(2012)^{61}\end{array}$ \\
\hline Elastic registration & $\begin{array}{l}\text { Elen et al. }(2008)^{21} \\
\text { De Craene et al. }(2012)^{34}\end{array}$ & Heyde et al. (2012) ${ }^{32}$ & Heyde et al. $(2011)^{56}$ & Jasaityte et al. $(2012)^{60}$ \\
\hline Model based & - & - & $\begin{array}{l}\text { Papademetris et al. }(2001)^{20} \\
\text { Papademetris et al. }(2002)^{49} \\
\text { Bouchez et al. }(2012)^{40, *}\end{array}$ & - \\
\hline
\end{tabular}

\footnotetext{
${ }^{*}$ Abstracts presented at scientific congresses.

†Only qualitative results are presented.
}

have correlated only moderately with those derived by 2D ST ( $r=$ $0.41-0.63)$. The limits of agreement between these techniques were rather large as well. For the block-matching approach, they were $\pm 17 \%$ (LS) and $\pm 24 \%$ (CS) with respect to the bias, while for the elastic registration approach, they were $\pm 9 \%$ (LS) and \pm $13 \%(C S)$.

In fact, the poor observed agreement between $2 \mathrm{D}$ and $3 \mathrm{D}$ techniques at the regional level might partially be due to the difficulty in matching corresponding LV segments. This may not be an important issue in a healthy heart, in which deformation is expected to be fairly homogeneous. However, in the presence of regional myocardial dysfunction, differences in strain values measured by two techniques might be induced by inaccurately matching segments. Moreover, the agreement between CS values measured with 2D and 3D strain estimation techniques can also be influenced by the discrepancies of endocardial border definition in the 2D and 3D data sets, in combination with a relatively large intramural gradient of this strain component. ${ }^{64}$ Nevertheless, the validity of 3D STE regional strain values still holds 


\begin{tabular}{|c|c|c|c|c|c|c|c|c|c|}
\hline \multirow[b]{2}{*}{ 3D STE approach } & \multirow[b]{2}{*}{ Validation study } & \multirow{2}{*}{$\begin{array}{l}\text { Study } \\
\text { setting }\end{array}$} & \multirow{2}{*}{$\begin{array}{l}\text { Reference } \\
\text { method }\end{array}$} & \multicolumn{6}{|c|}{ Correlation coefficient $(r)($ LOA [mean bias $\pm 1.96 \mathrm{SD}])^{\star}$} \\
\hline & & & & GLS & GCS & GRS & SLS & SCS & SRS \\
\hline \multirow[t]{12}{*}{ Block matching } & Duan et al. $(2007)^{50}$ & Clinical & MRI tagging & - & - & - & - & - & $0.91(2.18 \% \pm 3.47 \%)$ \\
\hline & Duan et al. $(2009)^{57}$ & In vivo & Sono & - & - & - & & $0.86(1.8 \pm 3.56$ & $\%)^{\S}$ \\
\hline & Seo et al. $(2009)^{51}$ & In vivo & Sono & - & - & - & 0.89 & 0.9 & 0.84 \\
\hline & $\begin{array}{l}\text { Maffessanti et al. } \\
(2009)^{55}\end{array}$ & Clinical & 2D ST & - & - & - & $0.49(0.4 \pm 16.8 \%)$ & $0.43(-2.8 \pm 24 \%)$ & $0.24(-0.8 \pm 52.2 \%)$ \\
\hline & $\begin{array}{l}\text { Ashraf et al. } \\
(2010)^{45, \dagger}\end{array}$ & In vitro & Sono & - & - & - & \multicolumn{2}{|c|}{$0.85^{\ddagger}(5.0 \pm 6.86 \%)$} & - \\
\hline & $\begin{array}{l}\text { Sahn et al. } \\
\qquad(2011)^{25, \dagger}\end{array}$ & In vitro & Sono & - & - & - & \multicolumn{2}{|c|}{$0.85(6.5 \pm 6.86 \%)$} & - \\
\hline & $\begin{array}{l}\text { Hjertaas et al. } \\
\qquad(2011)^{47, \dagger}\end{array}$ & In vitro & Sono & - & - & - & $\begin{array}{c}0.95 \text { to } 0.99 \\
(-0.02 \pm 2.45 \%) \\
\text { to } \\
(2.92 \pm 3.86 \%)\end{array}$ & $\begin{array}{c}0.80 \text { to } 0.99 \\
(-1.95 \pm 3.04 \%) \\
\text { to } \\
(-3.99 \pm 7.43 \%)\end{array}$ & - \\
\hline & Seo et al. $(2011)^{54}$ & In vivo & Sono & - & - & - & - & - & $0.87(\mathrm{ACR})(0.45 \pm 17.35 \%)$ \\
\hline & $\begin{array}{l}\text { Negishi et al. } \\
(2011)^{59}\end{array}$ & Clinical & 2D ST & $0.72(3.73 \pm 6.86 \%)$ & - & - & - & - & - \\
\hline & $\begin{array}{l}\text { Reant et al. } \\
(2012)^{24}\end{array}$ & Clinical & 2D ST & $0.91(1.3 \pm 4.4 \%)$ & - & - & - & - & - \\
\hline & $\begin{array}{l}\text { Hayat et al. } \\
(2012)^{58}\end{array}$ & Clinical & 2D ST & $0.86(0.5 \pm 4.29 \%)$ & - & - & - & - & - \\
\hline & Kleijn et al. $(2012)^{61}$ & Clinical & MRI tagging & - & $0.8(10 \pm 3.32 \%)$ & - & - & - & - \\
\hline \multirow[t]{3}{*}{ Elastic registration } & $\begin{array}{l}\text { Heyde et al. } \\
(2011)^{56}\end{array}$ & In vivo & Sono & - & - & - & 0.63 & 0.60 & - \\
\hline & $\begin{array}{l}\text { Jasaityte et al. } \\
(2012)^{60}\end{array}$ & Clinical & 2D ST & $0.93(2.94 \pm 5.19 \%)$ & $0.86(2.48 \pm 4.51 \%)$ & - & $\begin{array}{c}0.63 \\
(3.28 \pm 9.56 \%)\end{array}$ & $\begin{array}{c}0.41 \\
(3.27 \pm 12.92 \%)\end{array}$ & - \\
\hline & $\begin{array}{l}\text { Heyde et al. } \\
(2012)^{32}\end{array}$ & In vitro & Sono & - & - & - & 0.96 & 0.92 & 0.98 \\
\hline \multirow[t]{3}{*}{ Model based } & $\begin{array}{l}\text { Papademetris et al. } \\
\qquad(2001)^{20}\end{array}$ & In vivo & Sono & - & - & - & \multicolumn{3}{|c|}{$0.89^{\S}$} \\
\hline & $\begin{array}{l}\text { Papademetris et al. } \\
(2002)^{49}\end{array}$ & In vivo & MRI markers & - & - & - & 0.84 to $0.88^{\pi}$ & 0.46 to $0.73^{\pi}$ & 0.85 to $0.91^{\pi}$ \\
\hline & $\begin{array}{l}\text { Bouchez et al. } \\
(2012)^{40, \dagger}\end{array}$ & In vivo & Sono & - & - & - & 0.74 & 0.91 & 0.49 \\
\hline
\end{tabular}

$A C R$, Endocardial area change ratio; GCS, global CS; GLS, global LS; GRS, global RS; LOA, limits of agreement; SCS, segmental CS; SLS, segmental LS; Sono, sonomicrometry; SRS, segmental RS.

Studies are subdivided into those reporting data in an in vitro experimental setup, in an in vivo experimental setup, or in a clinical setting. When available, correlation coefficients and limits of agreement are reported for either global or segmental strain.

${ }^{*}$ Bias is reported as absolute strain value (3D speckle-tracking echocardiography - reference method).

${ }^{\dagger}$ Abstracts presented at scientific congresses.

${ }^{\ddagger}$ Correlations obtained for LS and CS values together.

All principal strain components.

IEach principal strain component individually.

"Range over different frame rate settings. 


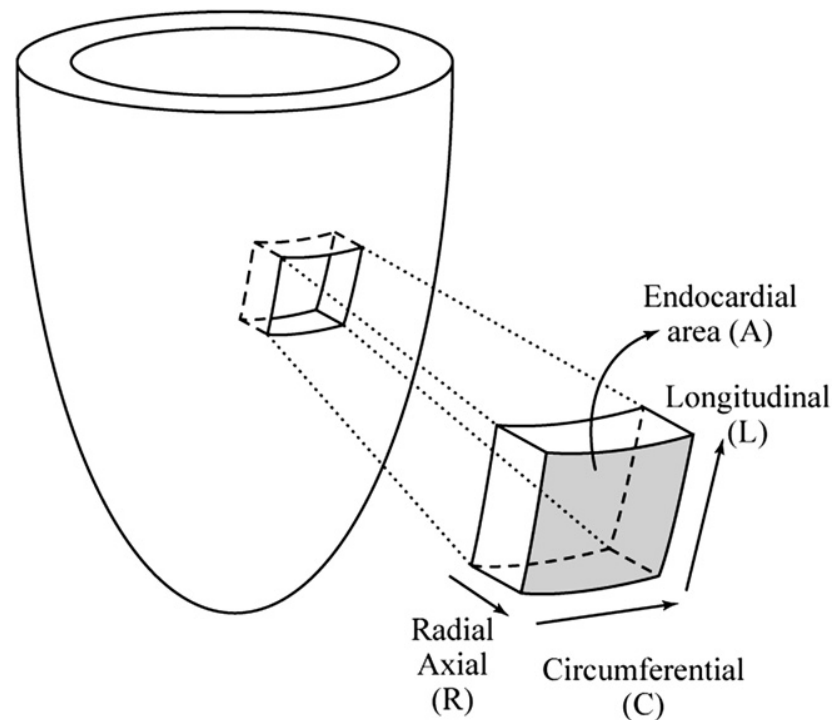

Figure 8 Conventions used to illustrate RS calculation. RS can also be computed from the other strain components or from the endocardial surface area strain during the cardiac cycle (for further details, see the Appendix).

true, as reflected by their good correlations with sonomicrometry in an in vivo experimental setting. ${ }^{20,40,49-51,56,57}$

\section{RS Estimates with 3D Speckle-Tracking Echocardiography}

As can be noted from Table 2, all current 3D strain estimation approaches can estimate LS and CS with acceptable accuracy, whereas the estimation of RS remains difficult. ${ }^{40,55}$ Either the correlation was moderate to poor or no correlations were found or reported. This suboptimal performance could be related to the fact that the spatial motion gradient must be calculated over a relatively small region because of the limited wall thickness, in combination with limited spatial resolution. Again, because of the orientation of the left ventricle in the volumetric data, beam density and consequently spatial resolution are lower in the radial direction than, for example, in the longitudinal direction. It is also worth mentioning that until the present day, RS estimation has been more difficult and prone to errors, even with $2 \mathrm{D}$ strain estimation techniques. ${ }^{65}$ Currently, the radial component may thus better be estimated by assuming volume conservation over the myocardium, as mentioned earlier (also see the Appendix).

\section{Reproducibility of 3D STE Measurements}

An equally important aspect for the clinical applicability of 3D speckle-tracking echocardiography is the reproducibility of the strain measurements. The reported intraobserver and interobserver variability for the different 3D STE approaches, listed for each strain component separately, is shown in Table 3. Note that in the text below as well as in Table 3, the variability of the strain measurements is reported as the ratio between the absolute difference and the mean of two repeated measurements expressed as a percentage.

To summarize, intraobserver variability of global 3D STE strain measurements obtained with different methods varied from $1 \%$ to $13 \%$, whereas interobserver variability varied from $2 \%$ to $14 \%$. The intraobserver and interobserver variability for regional 3D STE strain measurements ranged from $3 \%$ to $18 \%$ and from $5 \%$ to $25 \%$, respectively. In general, RS values showed higher variability than values of LS and CS. By means of comparison, the interobserver variability of DTI-derived segmental strain values ranged from $16 \%$ to $18 \%$. $^{66}$ The reported 2D ST intraobserver and interobserver variability was $11 \%{ }^{67}$ and $14 \%,{ }^{68}$ respectively. In contrast, a widely recognized parameter such as $\mathrm{LV}$ ejection fraction has intraobserver variability of $>10 \%$ when no contrast enhancement is used. ${ }^{69,70}$ The repeatability of current $3 \mathrm{D}$ strain measurements thus has the same order of variability, if not lower, than the other established techniques for the quantification of cardiac function.

Interexamination variability or test-retest repeatability of 3D speckle-tracking echocardiography has been assessed in only three studies. $^{24,30,62}$ Interexamination variability of the different global strain components ranged from $8 \%$ to $11 \%$ in one study. ${ }^{24}$ In two other studies performed in the same patient group, test-retest repeatability expressed as an intraclass correlation coefficient ranged from 0.41 to 0.77 for the different segmental strain components. ${ }^{30,62}$

It is worth noting that better reproducibility of strain measurements can be obtained for techniques with lower degrees of user interaction. Indeed, 3D STE methods using fully automatic or semiautomatic segmentation to indicate the region of interest tend to have better reproducibility than DTI, 2D ST, or other 3D STE methods in which contouring of the myocardial borders and segmentation must be done manually.

\section{Clinical Potential of 3D Speckle-Tracking Echocardiography}

Several recently published studies have shown the potential of $3 \mathrm{D}$ speckle-tracking echocardiography to replace 2D ST and DTI in a clinical setting in which the value of deformation imaging is already proven (e.g., the detection of myocardial ischemia). ${ }^{1-3}$ Evidently, full-volume data sets can be acquired in a more time efficient manner compared with multiple 2D cross-sections from several standard 2D planes. It also seems advantageous over 2D ST and DTI when significant and fast changes in loading conditions of the heart or heart rate can be expected, because a single acquisition is sufficient to obtain the deformation of all LV and right ventricular segments at once. Being able to provide a physician with a fast overview of the deformation properties of the heart further adds to this technique's appeal and makes it attractive in routine clinical practice.

Furthermore, 3D speckle-tracking echocardiography can provide a more robust measure of torsion, because it overcomes the major shortcomings of 2D ST by enabling the easy acquisition of parallel LV short-axis planes and precise measurement of the distance be tween them. Moreover, because 3D STE methods calculate the complex deformation of the entire myocardium, the extraction of shear strain components, which combine deformation in two different directions, will become feasible.

One of the biggest expectations in the future for 3D speckletracking echocardiography is its ability to provide better insight into cardiac physiology and disease processes. For example, instead of us ing a standardized 17-segment approach for LV segmentation (as proposed by the American Heart Association), ${ }^{71}$ more pathology-specific segments (e.g., infarct core, adjacent or remote myocardium, coronary artery territories) ${ }^{72}$ could be used to examine myocardial defor mation properties with 3D speckle-tracking echocardiography. Furthermore, measuring regional curvatures of the ventricle in a robust manner might soon become possible from volumetric data sets. As such, it would help estimate segmental LV load, which 


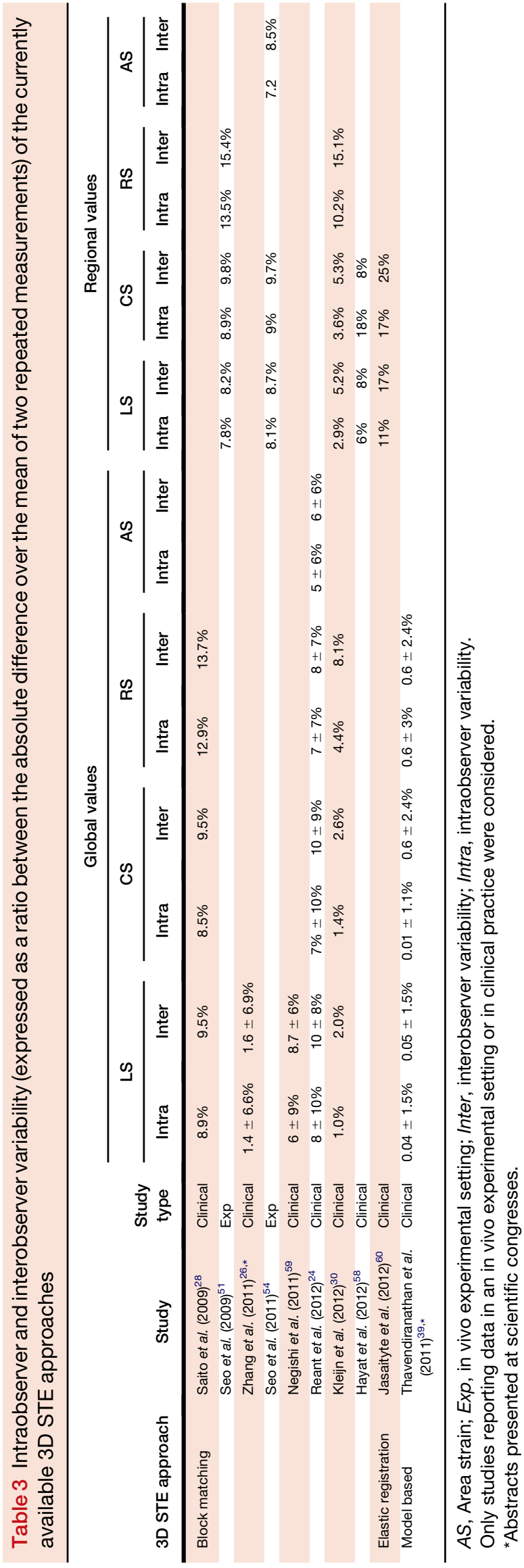

combined with strain measures would give more information about regional $\mathrm{LV}$ function.

\section{CURRENT LIMITATIONS OF THREE-DIMENSIONAL SPECKLE-TRACKING ECHOCARDIOGRAPHY}

General advantages and limitations of 3D STE approaches in comparison with DTI and 2D ST are summarized in Table 4. Indeed, good re producibility of strain values and time efficiency make 3D STE methods very attractive for clinical users. However, multiple factors can affect the performance and reliability of 3D strain estimation in certain clinical scenarios, such as stress echocardiography or the de tection of LV dyssynchrony. Some of these factors are intrinsic to the technology, while others can be avoided.

\section{Feasibility and Image Quality}

Most of the current ultrasound systems use ECG gating to produce volumetric data sets of sufficient temporal and spatial resolution. As such, the acquisition of volumetric data sets is limited to patients with no heart rhythm irregularities. Additionally, patients must be capable of holding their breath for at least four cardiac cycles to allow ECG gating. These technical factors may dramatically limit the number of patients in whom 3D speckle-tracking echocardiography is feasible.

High-quality volumetric data sets are crucial for reliable $3 \mathrm{D}$ strain estimates. In clinical practice, this can be challenging, because shadowing artifacts and signal dropouts often occur. It also requires a sufficient amount of training and skill to acquire high-quality data sets for strain quantification. ${ }^{73}$

The currently reported feasibility of 3D STE methods ranges from $63 \%$ to $83 \%{ }^{24,58-60}$ and is somewhat lower than that of $2 \mathrm{D}$ ST techniques $(80 \%-97 \%) .{ }^{18,74}$ Moreover, it should be noted that the feasibility of 3D speckle-tracking echocardiography was calculated af ter the exclusion of patients with arrhythmic disorders or patients who were not able to perform a sufficient breath hold.

\section{Intervendor Dependency of Strain Values}

As already mentioned, similar strain estimation methods can be implemented in many different ways (e.g., different regularization or postprocessing steps). Furthermore, nomenclature can differ among different vendors (e.g., instead of RS, area strain may be reported) and may mislead inexperienced users. It remains difficult to compare normal strain values among different commercial systems, largely be cause these platforms are closed (i.e., they act like black boxes). The associated high intervendor dependency of strain values is a known issue but is related not only to $3 \mathrm{D}$ STE techniques ${ }^{41}$ but also to $2 \mathrm{D}$ $\mathrm{ST}^{75}$ and DTI. ${ }^{75-77}$

However, it is worth mentioning that a working group of experts has recently been initiated by the European Association of Cardiovascular Imaging and the American Society of Echocardiography to work on the standardization of 2D ST software. Hopefully, similar measures will be undertaken in the future to standardize 3D STE software as well.

\section{Temporal Resolution}

Three-dimensional echocardiography comes at the expense of temporal resolution, which may limit its applicability in patients with high heart rates (e.g., during stress echocardiography and in patients with tachycardia). Moreover, because of the intrinsically low frame 
Table 4 Summary of main advantages and limitations of DTI, 2D ST, and 3D STE methods

DTI 2D ST 3D STE

\begin{tabular}{lccc}
\hline Feasibility & ++ & ++ & + \\
Reproducibility & ++ & ++ & $+++^{*}$ \\
Temporal resolution of strain curves & +++ & + & - \\
Spatial resolution of strain curves & ++ & + & + \\
Angle independency & - & + & ++ \\
Validation & & & \\
$\quad$ Simulated models & + & + & + \\
$\quad$ In vitro experimental setting & $+(+)$ & $+(+)$ & + \\
$\quad$ In vivo experimental setting & ++ & ++ & ++ \\
$\quad \begin{array}{l}\text { Comparison against other techniques } \\
\text { in clinical setting }\end{array}$ & ++ & +++ & + \\
$\quad \begin{array}{l}\text { Defined normal values } \\
\text { Time efficiency }\end{array}$ & +++ & +++ & - \\
$\quad \begin{array}{l}\text { Standardization of software packages } \\
\quad \text { offered by different vendors }\end{array}$ & - & ++ & $++^{*}$ \\
\hline
\end{tabular}

-, Poor or none; +, reasonable; ++, good; +++, very good.

*When automatic segmentation is used.

${ }^{\dagger}$ An expert group to work on the standardization of 2D ST software packages has been organized.

rate, the precise timing of peak systolic strain values is difficult. As such, one might question how reliably $3 \mathrm{D}$ speckle-tracking echocardiography can currently detect LV dyssynchrony (which may be defined by the standard deviation of time to peak systolic strain in 16 LV segments). However, some studies have shown that this might potentially provide interesting insights. ${ }^{78,79}$ The frame rate of $3 \mathrm{D}$ acquisitions can be increased by ECG gating, but stitching artifacts caused by breathing or probe motion may limit its use for functional quantification. Recently, advances in ultrasound beam forming have led to systems capable of acquiring real-time $3 \mathrm{D}$ volumes with reasonable temporal resolution. However, to date, no validation studies of those systems have been published.

Interestingly, Byram et al. ${ }^{80}$ investigated the influence of frame rate on the tracking performance of a block matching-based 3D STE method. For this purpose, an experimental setup with a deformable phantom was built, and images were acquired at volume rate between 50 and $1,000 \mathrm{~Hz}$. Motion estimates showed improvements up to a frame rate of $200 \mathrm{~Hz}$. Moreover, in a clinical setting, the influence of frame rate on the global strain values was evaluated recently by Negishi et al. ${ }^{59}$ They demonstrated that one of the block matching-based 3D STE approaches gives global LS values comparable with those obtained using 2D techniques at frame rates of 34 to 50 $\mathrm{Hz}$. Strain values extracted from acquisitions obtained at lower or higher frame rates did not correlate well. Similar results were reported in a phantom study by Hjertaas et al. ${ }^{47}$ The frame rate was modified in the range of 22 to $52 \mathrm{~Hz}$. The highest correlations against sonomicrometry for LS and CS were obtained in the middle of this range (37 $\mathrm{Hz}$ ). This is not surprising, because too low frame rate results in higher speckle decorrelation between subsequent frames, whereas too high frame rate results in a loss of spatial resolution and an associated coarser speckle pattern. Both of these situations are unfavorable for the performance of block matching-based techniques. It is worth mentioning in this context that a high heart rate has a similar effect as a low frame rate.

To date, there is no information available regarding the optimal frame rate for the other 3D STE techniques. However, in a simulation study,
Elen et al. ${ }^{21}$ showed that the accuracy of an elastic registration technique was not affected by an increased heart rate. This may be related to the underlying principles of image registration. In addition to local image features (speckle patterns), the method also takes global features (e.g., endocardial and epicardial borders) into account. As such, it may be less influenced by increased speckle decorrelation between frames.

\section{Strain Rate Estimation}

It has been elegantly shown that even though both strain and strain rate increase with dobutamine and decrease with esmolol infusion, they are not equal in estimating contractile function. ${ }^{81,82}$ In fact, strain is very much dependent on LV loading conditions, structure, and heart rate, thus making this parameter mainly a reflection of LV stroke volume. ${ }^{81,82}$ Strain rate, on the other hand, is less influenced by these factors. ${ }^{81,82}$ As such, strain rate can yield important insights into myocardial contractility and give a more complete view of regional myocardial mechanics.

Unfortunately, because of the low temporal resolution of 3D speckle-tracking echocardiography, none of the currently available 3D STE methods is suitable for strain rate measurements. Indeed, frame rates of 20 to $40 \mathrm{~Hz}$ might be sufficient for strain estimation, but frame rates $\geq 160 \mathrm{~Hz}$ are required to measure strain rate reliably. ${ }^{83}$

\section{Spatial Resolution}

Finally, all current 3D STE approaches seem to have difficulties estimating deformation in the basal parts of the left ventricle. The lowest correlation between the block matching-based 3D STE approach and 2D ST or triplane imaging was seen in the basal LV segments. ${ }^{59}$ The elastic registration-based 3D STE approach had the largest displacement estimation errors in the basal segments in simulated models. ${ }^{21}$ Consistently, in human data sets, the biggest differences in 2D and 3D LS values were seen in the basal segments as well. ${ }^{60}$ This is not entirely unexpected, as these segments move at the highest velocities during the cardiac cycle, which may be more difficult to measure accurately, especially given the already mentioned low frame rate of the current 3D ultrasound data sets. Moreover, it seems plausible that this is related to the spatial resolution as well. Because of the orientation of the left ventricle in the image volume, ultrasound beams diverge at the base, resulting in a lower spatial resolution and making tracking intrinsically harder.

\section{FUTURE DEVELOPMENTS AND CONCLUSIONS}

To date, different 3D STE methods have been proposed, all differing primarily in their underlying tracking mechanisms. However, to the best of our knowledge, no direct comparison studies have been reported so far. As such, there is currently no preferred method, and they all remain useful.

Initial experiences with 3D strain estimation are promising, although there is still room for improvement. The techniques can already successfully be applied for the estimation of global LV strain, but regional strain estimation remains challenging. In the future, more validation studies will be required to investigate their capability in detecting dysfunctional regions. Their biggest shortcoming is their inability to measure strain rate and the timing of peak strain values precisely, while the measurements of RS might be replaced by its calculation from LS and CS components.

Major research efforts are currently made to develop new advanced ultrasound transducers and beam-forming techniques that 
will improve spatial and temporal resolution. This will improve the performance of the current 3D STE techniques. In parallel, industry and academia are working on merging different tracking methods, combining their advantages while counteracting their individual disadvantages. Using more automatic segmentation strategies in the future should also have a positive effect on the reproducibility of strain measurements.

Furthermore, 3D STE software packages offered by different vendors should be standardized, and population-based studies should be initiated to define normal reference values for 3D STE global and regional strain values. Finally, large-scale clinical studies will be required to assess whether 3D STE strain values have any diagnostic or prognostic value in different clinical settings before these methods can effectively translate into clinical use.

\section{ACKNOWLEDGMENT}

We would like to thank Dr. Maja Cikes for the useful suggestions and careful reading of the manuscript.

\section{REFERENCES}

1. Hanekom L, Jenkins C, Jeffries L, Case C, Mundy J, Hawley C, et al. Incremental value of strain rate analysis as an adjunct to wall-motion scoring for assessment of myocardial viability by dobutamine echocardiography: a follow-up study after revascularization. Circulation 2005;112:3892-900.

2. Weidemann F, Wacker C, Rauch A, Bauer WR, Bijnens B, Sutherland GR, et al. Sequential changes of myocardial function during acute myocardial infarction, in the early and chronic phase after coronary intervention described by ultrasonic strain rate imaging. J Am Soc Echocardiogr 2006;19:839-47.

3. Chan J, Hanekom L, Wong C, Leano R, Cho GY, Marwick TH. Differentiation of subendocardial and transmural infarction using two-dimensional strain rate imaging to assess short-axis and long-axis myocardial function. J Am Coll Cardiol 2006;48:2026-33.

4. Weidemann F, Eyskens B, Mertens L, Di Salvo G, Strotmann J, Buyse G, et al. Quantification of regional right and left ventricular function by ultrasonic strain rate and strain indexes in Friedreich's ataxia. Am J Cardiol 2003;91:622-6.

5. Lee R, Hanekom L, Marwick TH, Leano R, Wahi S. Prediction of subclinical left ventricular dysfunction with strain rate imaging in patients with asymptomatic severe mitral regurgitation. Am J Cardiol 2004;94:1333-7.

6. Mertens L, Ganame J, Claus P, Goemans N, Thijs D, Eyskens B, et al. Early regional myocardial dysfunction in young patients with Duchenne muscular dystrophy. J Am Soc Echocardiogr 2008;21:1049-54.

7. Weidemann F, Niemann M, Ertl G, Stork S. The different faces of echocardiographic left ventricular hypertrophy: clues to the etiology. J Am Soc Echocardiogr 2010;23:793-801.

8. Ganame J, Claus P, Eyskens B, Uyttebroeck A, Renard M, D'hooge J, et al. Acute cardiac functional and morphological changes after Anthracycline infusions in children. Am J Cardiol 2007;99:974-7.

9. Jurcut R, Wildiers H, Ganame J, D’hooge J, De Backer J, Denys H, et al. Strain rate imaging detects early cardiac effects of pegylated liposomal Doxorubicin as adjuvant therapy in elderly patients with breast cancer. J Am Soc Echocardiogr 2008;21:1283-9.

10. Picano E, Lattanzi F, Orlandini A, Marini C, L'Abbate A. Stress echocardiography and the human factor: the importance of being expert. J Am Coll Cardiol 1991; 17:666-9.

11. Hoffmann R, Lethen H, Marwick T, Arnese M, Fioretti P, Pingitore A, et al. Analysis of interinstitutional observer agreement in interpretation of dobutamine stress echocardiograms. J Am Coll Cardiol 1996;27:330-6.

12. Heimdal A, Stoylen A, Torp H, Skjaerpe T. Real-time strain rate imaging of the left ventricle by ultrasound. J Am Soc Echocardiogr 1998;11:1013-9.
13. Kanai $H$, Hasegawa $H$, Chubachi N, Koiwa Y, Tanaka M. Noninvasive evaluation of local myocardial thickening and its color-coded imaging IEEE Trans Ultrason Ferroelectr Freq Control 1997;44:752-68.

14. D'hooge J, Heimdal A, Jamal F, Kukulski T, Bijnens B, Rademakers F, et al. Regional strain and strain rate measurements by cardiac ultrasound: principles, implementation and limitations. Eur J Echocardiography 2000;1: 154-70.

15. Kowalski M, Kukulski T, Jamal F, D'hooge J, Weidemann F, Rademakers F, et al. Can natural strain and strain rate quantify regional myocardial deformation? A study in healthy subjects. Ultrasound Med Biol 2001 ;27:1087-97.

16. Sutherland GR, Di Salvo G, Claus P, D'hooge I, Bijnens B. Strain and strain rate imaging: a new clinical approach to quantifying regional myocardial function. J Am Soc Echocardiogr 2004;17:788-802.

17. D'hooge J, Konofagou E, Jamal F, Heimdal A, Barrios L, Bijnens B, et al. Two-dimensional ultrasonic strain rate measurement of the human heart in vivo. IEEE Trans Ultrason Ferroelectr Freq Control 2002;49:281-6.

18. Leitman M, Lysyansky P, Sidenko S, Shir V, Peleg E, Binenbaum M, et al. Two-dimensional strain-a novel software for real-time quantitative echocardiographic assessment of myocardial function. J Am Soc Echocardiogr 2004;17:1021-9.

19. Perk G, Tunick PA, Kronzon I. Non-Doppler two-dimensional strain imaging by echocardiography-from technical considerations to clinical applications. J Am Soc Echocardiogr 2007;20:234-43.

20. Papademetris X, Sinusas AJ, Dione DP, Duncan JS. Estimation of 3D left ventricular deformation from echocardiography. Med Image Anal 2001; 5:17-28

21. Elen A, Choi HF, Loeckx D, Gao H, Claus P, Suetens P, et al. Three-dimensional cardiac strain estimation using spatio-temporal elastic registration of ultrasound images: a feasibility study. IEEE Trans Med Imaging 2008;27: 1580-91

22. Crosby J, Amundsen BH, Hergum T, Remme EW, Langeland S, Torp H 3-D speckle tracking for assessment of regional left ventricular function. Ultrasound Med Biol 2009;35:458-71

23. Lubinski MA, Emelianov SY, O'Donnell M. Speckle tracking methods for ultrasonicelasticity imaging using short-time correlation. IEEE Trans Ultrason Ferroelectr Freq Control 1999;46:82-96.

24. Reant P, Barbot L, Touche C, Dijos M, Arsac F, Pillois X, et al. Evaluation of global left ventricular systolic function using three-dimensional echocardiography speckle-tracking strain parameters. J Am Soc Echocardiogr 2012; 25:68-79.

25. Sahn DJ, Ashraf M, Balbach T, DesRochers K. A new 3D strain method for processing of $4 \mathrm{D}$ echo images can delineate regional myocardial dysfunction: validation against sonomicrometry. J Am Coll Cardiol 2011; 57(suppl):E707.

26. Zhang L, Gao I, Xie M, Yin P, Liu W, Li Y, et al. Three-dimensional global longitudinal strain analysis of left ventricle by real-time 3-D speckle track ing imaging in pediatric population: feasibility, reproducibility, maturational changes, and normal ranges. Circulation 2011;I24(suppl):A10777.

27. Schueler R, Sinning JM, Momcilovic D, Weber M, Ghanem A, Werner N, et al. Three-dimensional speckle-tracking analysis of left ventricular function after transcatheter aortic valve implantation. J Am Soc Echocardiogr 2012;25:827-34.

28. Saito K, Okura H, Watanabe N, Hayashida A, Obase K, Imai K, et al. Com prehensive evaluation of left ventricular strain using speckle tracking echocardiography in normal adults: comparison of three-dimensional and two-dimensional approaches. J Am Soc Echocardiogr 2009;22:1025-30.

29. Perez de Isla L, Balcones DV, Fernandez-Golfin C, Marcos-Alberca P, Almeria C, Rodrigo JL, et al. Three-dimensional-wall motion tracking: a new and faster tool for myocardial strain assessment: comparison with two-dimensional-wall motion tracking. J Am Soc Echocardiogr 2009;22: 325-30.

30. Kleijn SA, Aly MF, Terwee CB, van Rossum AC, Kamp O. Reliability of left ventricular volumes and function measurements using three-dimensional speckle tracking echocardiography. Eur Heart J Cardiovasc Imaging 2012; 13:159-68.

31. Kybic J, Unser M. Fast parametric elastic image registration. IEEE Trans Image Proc 2003; 12:1427-42. 
32. Heyde B, Cygan S, Choi HF, Lesniak-Plewinska B, Barbosa D, Elen A, et al Regional cardiac motion and strain estimation in three-dimensional echocardiography: a validation study in thick-walled univentricular phantoms IEEE Trans Ultrason Freq Control 2012;59:668-82.

33. Myronenko A, Song X, Sahn D. Maximum likelihood motion estimation in $3 \mathrm{D}$ echocardiography through non-rigid registration in spherical coordinates. Lecture Notes and Computer Sciences 2009;5528:427-36.

34. De Craene M, Piella G, Camara O, Duchateau N, Silva E, Doltra A, et al. Temporal diffeomorphic free-form deformation: application to motion and strain estimation from 3D echocardiography. Med Image Anal 2012;16:427-50.

35. Somphone O, Makram-Ebeid S, Cohen LD. Robust image registration based on a partition of unity finite element method. In: Proceedings of the Fifth IEEE International Symposium on Biomedical Imaging (ISBI 08). Paris, France: IEEE; 2008. pp. 1123-6.

36. Leung KY, Danilouchkine MG, van Stralen $M$, de Jong $N$, van der Steen AF, Bosch JG. Left ventricular border tracking using cardiac motion models and optical flow. Ultrasound Med Biol 2011;37:605-16.

37. Wang Y, Georgescu B, Houle H, Comaniciu D. Volumetric myocardial mechanics from $3 \mathrm{D}+\mathrm{t}$ ultrasound data with multi-modal tracking. Lecture Notes and Computer Sciences 2010;6364:184-93.

38. Yang L, Georgescu B, Zheng Y, Wang Y, Meer P, Comaniciu D. Prediction based collaborative trackers (PCT): a robust and accurate approach toward 3D medical object tracking. IEEE Trans Med Imaging 2011;30 1921-32.

39. Thavendiranathan $P$, Liu S, Calleja A, Houle H, Want $Y$, Duong $C$, et al. Automated 3-D "voxel" longitudinal, circumferential, and radial myocardial mechanis by real-time volume transthoracic echocardiography: feasibility and reproducibility. Presented at: American Society of Echocardiography Annual Scientific Session; 2011.

40. Bouchez S, Heyde B, Vandenheuvel M, Wang Y, Houle H, D'hooge I, et al. In-vivo validation of a new 3D myocardial strain estimation tool Presented at: American Society of Echocardiography Annual Scientific Session; 2012.

41. Gayat E, Ahmad H, Weinert L, Lang RM, Mor-Avi V. Reproducibility and inter-vendor variability of left ventricular deformation measurements by three-dimensional speckle-tracking echocardiography. J Am Soc Echocardiogr 2011;24:878-85.

42. Orderud F, Kiss G, Langeland S, Remme EW, Torp HG, Rabben SI. Com bining edge detection with speckle-tracking for cardiac strain assessment in 3D echocardiography. IEEE Trans Med Imag 2008;1959-62.

43. Langeland S, Rabben SI, Heimdal A, Gerard O. 4D strain: validation of new 3D speckle tracking and left ventricular function tool in simulated echocardiographic data. Eur J Echocardiography 2010;11 (suppl):ii86-7.

44. Lesniak-Plewinska B, Cygan S, Kaluzynski K, D’hooge I, Zmigrodzki I, Kowalik E, et al. A dual-chamber, thick-walled cardiac phantom for use in cardiac motion and deformation imaging by ultrasound. Ultrasound Med Biol 2010;36:1145-56.

45. Ashraf M, DesRochers K, Sahn DJ. A new high resolution 3D echo based strain method gives robust characterization of myocardial mechanics: an in vitro validation study. Circulation 2010;A12781.

46. Jia C, Kim K, Kolias TJ, Rubin JM, Weitzel WF, Yan P, et al. 4D elasticity imaging of PVA LV phantom integrated with pulsatile circulation system using 2D phased array. In: Proceedings of the IEEE Ultrasonics Symposium. Piscataway, NJ: IEEE; 2007. pp. 876-9.

47. Hjertaas JJ, Fossa H, Dybdahl GL, Gruner R, Lunde P, Matre K. Accuracy of real-time single and multi beat $3 \mathrm{D}$ speckle tracking echocardiography in vitro. Eur J Echocardiography 2011;12(suppl):ii5-6.

48. Shi P, Sinusas AJ, Constable RT, Ritman E, Duncan JS. Point-tracked quantitative analysis of left ventricular motion from 3-D image sequences. IEEE Trans Med Imag 2000;19:36-50.

49. Papademetris X, Sinusas AJ, Dione DP, Constable RT, Duncan JS. Estimation of 3-D left ventricular deformation from medical images using biomechanical models. IEEE Trans Med Imaging 2002;21:786-800.

50. Duan Q, Homma S, Laine AF. Analysis of $4 \mathrm{D}$ ultrasound for dynamic measures of cardiac function. In: Proceedings of the IEEE Ultrasonics Symposium. New York, NY: IEEE; 2007. pp. 463-73.
51. Seo Y, Ishizu T, Enomoto Y, Sugimori H, Yamamoto M, Machino T, et al. Validation of 3-dimensional speckle tracking imaging to quantify regional myocardial deformation. Circ Cardiovasc Imaging 2009;2:451-9.

52. Jia C, Kolias TJ, Rubin JM, Q. W, Thiele K, Yan P, et al. 3D elasticity imaging on an open-chest dog heart. In: Proceedings of the IEEE Ultrasonics Symposium. Piscataway, NJ: IEEE; 2009:155-8.

53. Ashraf M, Myronenko A, Nguyen T, Inage A, Smith W, Lowe RI, et al. Defining left ventricular apex-to-base twist mechanics computed from highresolution 3D echocardiography: validation against sonomicrometry. JACC Cardiovasc Imaging 2010;3:227-34.

54. Seo Y, Ishizu T, Enomoto Y, Sugimori H, Aonuma K. Endocardial surface area tracking for assessment of regional LV wall deformation with 3D speckle tracking imaging. JACC Cardiovasc Imaging 2011;4:358-65.

55. Maffessanti F, Nesser HJ, Weinert L, Steringer-Mascherbauer R, Niel J, Gorissen W, et al. Quantitative evaluation of regional left ventricular function using three-dimensional speckle tracking echocardiography in patients with and without heart disease. Am J Cardiol 2009;104:1755-62.

56. Heyde B, Jasaityte R, Bouchez S, Vandenheuvel M, Loeckx D, Claus $P$, et al. Three-dimensional myocardial strain estimation from volumetric ultrasound: experimental validation in an animal model. In: Proceedings of the IEEE Ultrasonics Symposium. Piscataway, NJ: IEEE; 2011. pp. 1862-5.

57. Duan Q, Parker KM, Lorsakul A, Angelini ED, Hyodo E, Homma S, et al. Quantitative validation of optical flow based myocardial strain measures using sonomicrometry. In: Proceedings of the Sixth IEEE International Symposium on Biomedical Imaging (ISBI '09). Boston, Massachusetts: IEEE; 2009. pp. 454-7.

58. Hayat D, Kloeckner M, Nahum J, Ecochard-Dugelay E, Dubois-Rande JL, Jean-Francois $\mathrm{D}$, et al. Comparison of real-time three-dimensional speckle tracking to magnetic resonance imaging in patients with coronary heart disease. Am J Cardiol 2012;109:180-6.

59. Negishi K, Negishi T, Agler DA, Plana JC, Marwick TH. Role of temporal resolution in selection of the appropriate strain technique for evaluation of subclinical myocardial dysfunction. Echocardiography 2011;29:334-9.

60. Jasaityte R, Heyde B, Ferferieva V, Amundsen B, Barbosa D, Loeckx D, et al. Comparison of a new methodology for the assessment of 3D myocardial strain from volumetric ultrasound with 2D speckle tracking. Int J Cardiovasc Imaging 2012;28:1049-60.

61. Kleijn SA, Brouwer WP, Aly MF, Russel IK, de Roest GJ, Beek AM, et al Comparison between three-dimensional speckle-tracking echocardiography and cardiac magnetic resonance imaging for quantification of left ventricular volumes and function. Eur Heart J Cardiovasc Imaging 2012;13: 834-9.

62. Kleijn SA, Aly MF, Terwee CB, van Rossum AC, Kamp O. Three-dimensional speckle tracking echocardiography for automatic assessment of global and regional left ventricular function based on area strain. J Am Soc Echocardiogr 2011;24:314-21.

63. Galderisi M, Esposito R, Schiano-Lomoriello V, Santoro A, Ippolito R, Schiattarella $\mathrm{P}$, et al. Correlates of global area strain in native hypertensive patients: a three-dimensional speckle-tracking echocardiography study. Eur Heart J Cardiovasc Imaging 2012;13:730-8.

64. Bogaert J, Rademakers FE. Regional nonuniformity of normal adult human left ventricle. Am J Physiol Heart Circ Physiol 2001;280:H610-20.

65. Langeland S, Wouters PF, Claus P, Leather HA, Bijnens B, Sutherland GR, et al. Experimental assessment of a new research tool for the estimation of two-dimensional myocardial strain. Ultrasound Med Biol 2006;32: 1509-13

66. Kuznetsova T, Herbots L, Richart T, D'hooge J, Thijs L, Fagard RH, et al Left ventricular strain and strain rate in a general population. Eur Heart ] 2008;29:2014-23.

67. Hurlburt HM, Aurigemma GP, Hill JC, Narayanan A, Gaasch WH, Vinch CS, et al. Direct ultrasound measurement of longitudinal, circumferential, and radial strain using 2-dimensional strain imaging in normal adults. Echocardiography 2007;24:723-31.

68. Thorstensen A, Dalen H, Amundsen BH, Aase SA, Stoylen A. Reproduc ibility in echocardiographic assessment of the left ventricular global and re gional function, the HUNT study. Eur J Echocardiography 2010;11: 149-56. 
69. Galema TW, Geleijnse ML, Yap SC, van Domburg RT, Biagini E, Vletter WB, et al. Assessment of left ventricular ejection fraction after myocardial infarction using contrast echocardiography. Eur J Echocardiography 2008;9:250-4.

70. McGowan JH, Cleland JG. Reliability of reporting left ventricular systolic function by echocardiography: a systematic review of 3 methods. Am Heart I 2003;146:388-97.

71. Cerqueira MD, Weissman NJ, Dilsizian V, Jacobs AK, Kaul S, Laskey WK, et al. Standardized myocardial segmentation and nomenclature for tomographic imaging of the heart: a statement for healthcare professionals from the Cardiac Imaging Committee of the Council on Clinical Cardiology of the American Heart Association. Circulation 2002;105:539-42.

72. Masci PG, Dymarkowski S, Rademakers FE, Bogaert J. Determination of regional ejection fraction in patients with myocardial infarction by using merged late gadolinium enhancement and cine MR: feasibility study. Radiology 2009;250:50-60.

73. Ryan T, Armstrong WF, Khandheria BK. Task Force 4 : training in echocardiography endorsed by the American Society of Echocardiography. J Am Coll Cardiol 2008;51:361-7.

74. Marwick TH, Leano RL, Brown J, Sun JP, Hoffmann R, Lysyansky P, et al. Myocardial strain measurement with 2-dimensional speckle-tracking echocardiography: definition of normal range. JACC Cardiovasc Imaging 2009;2:80-4.

75. Koopman LP, Slorach C, Hui W, Manlhiot C, McCrindle BW, Friedberg $\mathrm{MK}$, et al. Comparison between different speckle tracking and color tissue Doppler techniques to measure global and regional myocardial deformation in children. J Am Soc Echocardiogr 2010;23: 919-28.
76. Kjaergaard J, Korinek J, Belohlavek M, Oh JK, Sogaard P, Hassager C. Accuracy, reproducibility, and comparability of Doppler tissue imaging by two high-end ultrasound systems. J Am Soc Echocardiogr 2006;19:322-8.

77. Martensson M, Bjallmark A, Brodin LA. Evaluation of tissue Dopplerbased velocity and deformation imaging: a phantom study of ultrasound systems. Eur J Echocardiography 2011;12:467-76.

78. Thebault C, Donal E, Bernard A, Moreau O, Schnell F, Mabo P, et al. Realtime three-dimensional speckle tracking echocardiography: a novel technique to quantify global left ventricular mechanical dyssynchrony. Eur J Echocardiography $2011 ; 12: 26-32$.

79. Matsumoto K, Tanaka H, Tatsumi K, Miyoshi T, Hiraishi M, Kaneko A, et al. Left ventricular dyssynchrony using three-dimensional speckle-tracking imaging as a determinant of torsional mechanics in patients with idiopathic dilated cardiomyopathy. Am J Cardiol 2012;109:1197-205.

80. Byram B, Holley G, Giannantonio D, Trahey G. 3-D phantom and in vivo cardiac speckle tracking using a matrix array and raw echo data. IEEE Trans Ultrason Ferroelectr Freq Control 2010;839-54.

81. Ferferieva V, Van den Bergh A, Claus P, Jasaityte R, Veulemans $P$, Pellens $M$, et al. The relative value of strain and strain rate for defining in trinsic myocardial function. Am J Physiol Heart Circ Physiol 2012;302: H188-95.

82. Weidemann F, Jamal F, Sutherland GR, Claus P, Kowalski M, Hatle L, et al. Myocardial function defined by strain rate and strain during alterations in inotropic states and heart rate. Am J Physiol Heart Circ Physiol 2002;283: H792-9.

83. Sutherland GR, Hatle L, Rademakers FE, Claus P, D'hooge J, Bijnens BH. Doppler myocardial imaging. A textbook. Hasselt, Belgium: BSWK bvba, Scientific Consulting and Publishing; 2002. 


\section{APPENDIX}

\section{Radial Strain Estimation}

Because a direct estimation of the RS component remains difficult, some authors and vendors have proposed computing it from the other strain components. This appendix highlights how these calculations can be done and what assumptions they are based on

Consider a small myocardial element, as shown in Figure 8. In reality, the surfaces of this element are curved, but locally this element may be considered a cube with initial dimensions $R, L$, and $C$ in the radial, longitudinal, and circumferential directions, respectively. The initial volume $\left(V_{0}\right)$ of this cube is simply the product of its sides: $R L C$. Upon deformation, the length of the sides of the cube will change. If we assume these length changes are represented by $\Delta R$, $\Delta L$, and $\Delta C$ for the radial, longitudinal, and circumferential directions, respectively, the volume $(V)$ of the cube after deformation is $(R+\Delta R)(L+\Delta L)(C+\Delta C)$. A change in volume $(\Delta V)$ can then be written as

$$
\Delta V=V-V_{0}=(R+\Delta R)(L+\Delta L)(C+\Delta C)-R L C
$$

If the volume is conserved during deformation (i.e., by assuming myocardial incompressibility), $\Delta V$ must equal zero, implying from the above equation that

$$
(R+\Delta R)(L+\Delta L)(C+\Delta C)-R L C=0 .
$$

Dividing both sides of this equation by $R L C$ gives

$$
(1+\Delta R / R)(1+\Delta L / L)(1+\Delta C / C)=1 .
$$

Noting that $\Delta R / \mathrm{R}$ is the change in length of the radial side of the cube with respect to its original length $(R)$, this is the RS. With similar reasoning for the longitudinal and circumferential directions, we thus obtain

$$
(1+\mathrm{RS})(1+\mathrm{LS})(1+\mathrm{CS})=1
$$

When expanding the above product, we find

$$
1+\mathrm{RS}+\mathrm{LS}+\mathrm{CS}+\mathrm{RS} \cdot \mathrm{CS}+\mathrm{RS} \cdot \mathrm{LS}+\mathrm{LS} \cdot \mathrm{CS}+\mathrm{RS} \cdot \mathrm{CS} \cdot \mathrm{LS}=1 .
$$

If the strain values are small (i.e., RS, CS, and LS are much smaller than 1), their products become even smaller and can, to a first order of approximation, be neglected. As such, in the case of small deformations, equation A5 further simplifies to

$$
\mathrm{RS}+\mathrm{LS}+\mathrm{CS} \approx 0
$$

or

$$
\mathrm{RS} \approx-(\mathrm{LS}+\mathrm{CS})
$$

stating that RS is the negative sum of LS and CS.

Using the above notations, the endocardial area $(A)$ of the cube can simply be written as LC.

Area strain (AS) is defined as the relative change in surface area over the cardiac cycle and can thus be written as

$$
\mathrm{AS}=[(A+\Delta A)-A]=[(L+\Delta L)(C+\Delta C)-\mathrm{LC}] / \mathrm{LC},
$$

which reduces to

$$
\mathrm{AS}=(1+\Delta L / L)(1+\Delta C / C)-1
$$

or

$$
\mathrm{AS}=(1+\mathrm{LS})(1+\mathrm{CS})-1
$$

Note that this deformation parameter is also referred to as area change ratio by some vendors.

Again, if a small deformation can be assumed, then equation A10 further simplifies to

$$
A S \approx(L S+C S) \text {. }
$$

In other words, AS is the sum of LS and CS. From equation A7, it is then obvious that RS is simply the negative of AS (when assuming volume conservation):

$\mathrm{RS} \approx-\mathrm{AS}$ 